\title{
Uma experiência da inserção de noções de matemática financeira no Ensino Técnico
}

\author{
Luis Antonio S Vasconcellos ${ }^{1}$ \\ FC/Unesp/Bauru \\ Fernando Trindade Fanali ${ }^{2}$ \\ Fatec/Lins
}

\begin{abstract}
Resumo. Este trabalho propõe a inserção de atividades envolvendo noções de matemática financeira no conteúdo desenvolvido para os alunos do útimo ano do ensino médio de uma Escola, no caso de ensino técnico. Entende-se que apesar da formação fundamentada na conclusão do ensino médio, há defasagem de alguns temas, dentre estes, a matemática financeira, apesar da sua utilização frequente. Dessa forma, foram apresentados alguns tópicos de matemática financeira e finanças pessoais e como aplicação, foram desenvolvidas algumas dinâmicas com os alunos dos primeiros anos do ensino médio e dos cursos técnicos de administração (idades entre 16 e 60 anos) de uma Escola Técnica na cidade de Lins-SP, com a finalidade que atuassem como consultores financeiros em quatro atividades: cheque especial, crédito pessoal e habitacional e previdência privada. Um espaço foi designado para cada uma das atividades que tiveram em torno de 300 pessoas, sendo na sua maioria, alunos do período noturno da escola. Ao final, apresenta-se uma análise dos problemas discutidos, bem como dos conteúdos utilizados nas discussões e soluções dos problemas propostos, uma visão geral das experiências vividas pelos alunos.
\end{abstract}

Palavras-chave. Matemática Financeira. Economia. Finanças Pessoais, Educação Financeira, Ensino Técnico, Escola Pública.

\section{Introdução}

No Brasil, as mudanças trazidas principalmente pela estabilização da economia e a queda da inflação a partir do Plano Real (1994) alteraram a forma como a população lida com seus recursos financeiros. A educação financeira pessoal é fundamental na sociedade brasileira, visto que influencia diretamente as decisões econômicas dos indivíduos e das famílias [1]. Já pode ser observado o surgimento de iniciativas para a criação de um cenário que possibilite uma maior difusão de informações financeiras para a população. A alfabetização financeira é um processo de responsabilidade do país, das escolas, do governo e das instituições privadas, envolvendo vários atores sociais. A Bolsa de Valores de São Paulo (BOVESPA) disponibiliza, para a sociedade, com o seu Programa Educacional, conceitos sobre o tema "educação financeira" através de cursos e palestras [12]. O Banco Central do Brasil (BACEN) desenvolveu o Programa de Educação Financeira para orientar melhor as pessoas sobre a importância do planejamento financeiro e também para auxiliar os indivíduos a entender melhor o funcionamento da economia, assim como de seus agentes e instrumentos. A partir de outubro de 2010, a Sub-Chefia da Casa Civil da Presidência da República, instituiu a Estratégia Nacional de Educação Financeira - ENEF com a finalidade de promover a educação financeira e previdenciária e contribuir para o fortalecimento da

\footnotetext{
${ }^{1}$ luis.a.vasconcellos@unesp.br.

2 fernandotrindadefanali@yahoo.com.br.
} 
cidadania, a eficiência e solidez do sistema financeiro nacional e a tomada de decisões conscientes por parte dos consumidores. O Programa Educação Financeira nas Escolas é uma ação relevante e estratégica para toda a sociedade brasileira. Ao inserí-lo na formação dos estudantes, o programa contribui para o desenvolvimento da cultura de planejamento, prevenção, poupança, investimento e consumo consciente. Dentre estes, conceitos ligados a matemática financeira [5] e a economia nas séries iniciais da educação tem se tornado um desafio visto o pouco interesse do tema na educação básica, apesar do destaque na mídia e das instituições financeiras. Entende-se que há uma necessidade de desenvolver conteúdos e estratégias que sejam significativos e aplicados na vida do aluno [6]. Este trabalho organiza-se da seguinte forma: nas seções 2 a 4, são apresentados os conteúdos teóricos abordando alguns tópicos da matemática financeira e finanças pessoais. Na seção 5, apresentam-se as quatro atividades desenvolvidas como aplicações em finanças: utilização do cheque especial, crédito pessoal, previdência privada e financiamento imobiliário. Tais temas foram discutidos na forma de dinâmicas que envolveram consultorias realizadas em espaços criados para esta finalidade com a participação de alunos mais diretamente envolvidos (consultores) e público externo. Após as descrições de cada atividade, foram comentadas as situações apresentadas e por fim, as considerações finais.

\section{Juros}

De acordo com [1], as taxas de juros são utilizadas de maneira a remunerar: o risco envolvido na operação (empréstimo ou aplicação), a perda do poder de compra do capital motivada pela inflação; o capital emprestado/aplicado e a remuneração do fator capital utilizado durante certo período de tempo. A soma do produto do capital $C$ pela taxa i por um período n é denominada Juros Simples $(\mathrm{J})$. A soma desses juros com o capital aplicado é denominado Montante, (M). Portanto,

$$
J=\underbrace{C \cdot i+\cdots+C \cdot i}_{n \text { vezes }}
$$

e como o montante é a soma do capital e os juros $M=C+J$ então

$$
M=C \cdot(1+i \cdot n) .
$$

Para fins didáticos, demonstra-se que o montante dos juros simples baseia-se em uma progressão aritmética. Há duas modalidades de descontos: o Racional (por dentro) e o Comercial (Bancário). O desconto racional Dr é a diferença entre o título N (valor nominal do título) e seu valor atual A definido como

$$
\begin{aligned}
& D r=N-A \\
& A=\frac{N}{1+i \cdot n} .
\end{aligned}
$$

Substituindo (3) em (4):

$$
D r=\frac{N \cdot i \cdot n}{1+i \cdot n}
$$

A partir de (5) calcula-se o desconto racional obtido de determinado valor nominal $N$, a uma taxa simples de juros $i$ a um prazo determinado de antecipação $n$, sendo que

$$
D c=N \cdot i \cdot n
$$




$$
A=N \cdot(1-i \cdot n)
$$

representam respectivamente o desconto comercial e o valor atual da dívida.

\section{$2.1 \quad$ Juros compostos}

Nesta modalidade, os juros são capitalizados gerando uma progressão geométrica [10], considerando o capital(C), a taxa(i), os períodos de capitalização (n), os juros(J) e montante (M). Assim

$$
M=C \cdot(1+i)^{n},
$$

e como $J=M-C$, então:

$$
J=C \cdot\left[(1+i)^{n}-1\right] .
$$

\section{Capitalização contínua}

A capitalização contínua é restrita a certas operações em que os fluxos de caixa encontram-se distribuídos no tempo e produz um resultado final maior que o calculado pelas condições de juros compostos, sendo expressa por:

$$
M_{e}=C \cdot e^{(i \cdot n)},
$$

onde $M_{e}$ representa o montante de capitalização contínua, C o Capital aplicado e i a taxa da aplicação. Se for necessário um capital a longo prazo e há uma programação de depósitos nesse investimento, então

$$
M=D \cdot \frac{\left[(1+i)^{n}-1\right]}{i},
$$

sendo D o valor do depósito periódico.

\subsection{Fluxo de Caixa e Financiamentos}

O valor presente de um fluxo de caixa uniforme para uma taxa periódica de juros é determinado pelo somatório dos valores presentes em cada um de seus valores de acordo com a expressão

$$
P V=P M T\left[(1+i)^{-1}+(1+i)^{-2}+(1+i)^{-3}+\cdots+(1+i)^{-n+1}+(1+i)^{-n}\right],
$$

denominada de Fator de Valor Presente, representada por $F P V(i, n)$. Com isso, a formulação genérica do valor presente assume a expressão:

$$
P V=P M T \cdot F P V(i, n),
$$

onde

$$
F P V(i, n)=\frac{(1+i)^{n}-1}{(1+i)^{n} \cdot i}
$$

conduzindo à fórmula do valor presente de um fluxo de caixa uniforme definida por

$$
P V=P M T\left[\frac{1-(1+i)^{-n}}{i}\right]=P M T \cdot F P V(1, n) .
$$


Outro fator importante nestas operações é a carência. Um exemplo de cálculo de carência é o Financiamento Estudantil do Ensino Superior (FIES) cuja equação com pagamentos uniformes e periódicos é descrita por

$$
P V=\frac{P M T \cdot(1+i)^{n+c} \cdot i}{(1+i)^{n}-1}
$$

\subsection{Finanças Pessoais}

Entende-se por finanças pessoais o estudo e a aplicação de conceitos financeiros nas decisões financeiras de uma pessoa (ou de uma família). Para tal, são consideradas todas as características da família e os diversos eventos financeiros que esta atravessa, bem como a sua fase de vida, de modo a proporcionar um planejamento financeiro adequado às suas necessidades [4,9]. A construção rigorosa de um orçamento permite determinar se as contas estão deficitárias ou superavitárias, são resumidas de acordo com a identificação: situação atual, padrões de consumo e de poupança, despesas passíveis de eliminação; planejamento do consumo nos meses seguintes e definição de objetivos de poupança $[2,3]$.

\section{Aplicações das finanças pessoais}

Para implementação dos conceitos apresentados, foram propostas quatro atividades: utilização do cheque especial, crédito pessoal, previdência privada e financiamento de imóveis e uma dinâmica para o seu desenvolvimento [7]. As turmas foram divididas em 4 grupos que se revezaram nas atividades de consultoria. Para cada consultoria, foi utilizado um tutorial das atividades (preparado para cada atividade) dando base de argumentação nas explicações. A seguir, descrevemos mais especificamente cada atividade.

\subsection{Atividade I - Cheque Especial}

Um dos assuntos mais frequentes no cotidiano da população, no tocante a crédito, diz respeito à utilização do cheque especial. Para início das atividades foram disponibilizadas taxas de alguns dos bancos mais utilizados pela população (tabela 1).

Tabela 1: Cheque Especial - fonte:https://portal.febraban.org.br/

\begin{tabular}{|c|c|c|c|}
\hline Bancos & Dez/16 & Jan/18 & Variação \\
\hline C.E.Federal & $12,32 \%$ & $12,47 \%$ & $1,22 \%$ \\
\hline B. Brasil & $12,31 \%$ & $12,48 \%$ & $1,38 \%$ \\
\hline Bradesco & $12,45 \%$ & $12,15 \%$ & $-2,41 \%$ \\
\hline Itaú & $12,98 \%$ & $12,75 \%$ & $-1,77 \%$ \\
\hline Santander & $15,25 \%$ & $14,73 \%$ & $-3,41 \%$ \\
\hline
\end{tabular}

Com a finalidade de exibir uma situação do impacto da utilização do cheque especial nas finanças do correntista, estabeleceu-se uma taxa média de $12 \%$ a m.. Durante essa atividade, uma participante relatou que estava utilizando $\mathrm{R} \$ 300,00$ no limite do cheque especial e não conseguia cobrí-lo há 3 meses. A mesma exibiu o extrato para o consultor que, após análise, demonstrou que a taxa era de 14,76\% ao mês. Utilizando os recursos implementados durante o início da atividade, exibiu-se a atual situação que demonstrava um saldo devedor de $\mathrm{R} \$ 453,41$. Conclui-se desta 
atividade que muitos dos presentes utilizavam desta modalidade, mas desconheciam as taxas e saldos devedores.

\subsection{Atividade II - Crédito Pessoal}

Complementando a atividade anterior, outra consultoria abordou o crédito Pessoal que é uma modalidade de crédito para vários tipos de finalidades. Apesar de ser prática comum entre os bancos, as taxas e prazos diferem-se muito. O primeiro passo dessa atividade foi verificar as alíquotas cobradas por algumas das principais instituições financeiras. No portal do Banco Central (www.bcb.gov.br/estatistica), encontram-se as taxas praticadas por todos os bancos. Com a implantação do crédito consignado, verificou-se um aumento significativo desta modalidade de crédito. Analogamente à atividade anterior, o primeiro passo foi explicitar como se calcula o valor da prestação para um determinado empréstimo. Para mostrar uma situação mais próxima da realidade, foi exibida uma tabela de taxas praticadas por todos os bancos (https://portal.febraban.org.br). Foi proposto aos consultores o seguinte exemplo para introdução do assunto nas exposições: é solicitado um empréstimo no valor de $\mathrm{R} \$ 5.000,00$ à taxa de $2,5 \%$ ao mês que serão pagos em 24 vezes pelo método SAF (Sistema de Amortização Francês). Determinar o valor da prestação, considerando que não houve entrada.Utilizando a equação

$$
P=\frac{V \cdot i \cdot(1+i)^{n}}{(1+i)^{n}-1}
$$

com os dados, determinou-se que $\mathrm{P}=\mathrm{R} \$ 279,57$. Após este passo, foi apresentada uma planilha de financiamentos (tabela 2) utilizando o SAF para exposição na consultoria. Ainda, foram exibidos os cálculos das prestações e a explicação do funcionamento da amortização, facilitando a interpretação e discussão desta modalidade. De acordo com [3], tais resultados também podem ser obtidos utilizando-se equações de diferenças.

Tabela 2: Crédito Pessoal

\begin{tabular}{|c|c|c|c|c|}
\hline Parcela & Amortização & Juros & Prestação & Saldo Devedor \\
\hline 1 & 154,56 & 125,00 & 279,56 & 4845,44 \\
\hline 2 & 158,43 & 121,14 & 279,56 & 4687,01 \\
\hline 3 & 162,39 & 117,18 & 279,56 & 4524,62 \\
\hline$\cdot$ & $\ldots \ldots$ & $\ldots \ldots$ & $\ldots \ldots$ & $\ldots \ldots$ \\
\hline 22 & 259,60 & 19,96 & 279,56 & 538,84 \\
\hline 23 & 266,09 & 13,47 & 279,56 & 272,75 \\
\hline 24 & 272,75 & 6,82 & 279,56 & 0,00 \\
\hline
\end{tabular}

Foram apresentadas diversas situações envolvendo o tema e, em muitos casos, constatou-se que os interessados procurariam as instituições no sentido de discutir melhores condições para os contratos em vigência. Conclui-se desta atividade e da anterior que, diante das situações apresentadas, uma grande maioria demonstra total desconhecimento de cálculo e principalmente das taxas e do impacto nas suas vidas.

\subsection{Atividade III - Previdência Privada}

A partir de meados de 2018, a reforma da previdência passou a ter uma intensa cobertura por parte da mídia, devido ao projeto proposto pelo Governo. Para esta consultoria, foi realizada uma pesquisa sobre taxas utilizadas, optando-se por uma taxa de $0,8 \%$ a.m. com depósitos mensais 
de $\mathrm{R} \$ 1.000,00$, para um período de 20 anos. Utilizando a expressão da capitalização contínua, chegou-se ao valor de $\mathrm{R} \$ 721.131,21$. Diante desta situação, os participantes propuseram várias possibilidades de análise aos consultores. Uma situação que chamou a atenção, foi a seguinte: Um participante (56 anos), aluno de um dos cursos, questionou se seria possível atingir $\mathrm{R} \$ 1.000 .000,00$ num fundo de aplicação de $1 \%$ a.m. até os 60 anos. Da capitalização contínua,

$$
D=\frac{M \cdot i}{(1+i)^{n}-1}
$$

conclui-se que a partir de um depósito mensal de $R$ 16.332,93, seria possível atingir a quantia de $R \$ 1.000 .000,00$, conforme a solicitação da consulta.

\subsection{Atividade IV - Financiamento de imóveis}

Para esta atividade, foi desenvolvida uma planilha para simulação de financiamento de imóveis baseada no sistema SAC. Utilizou-se o exemplo a seguir.

Um imóvel no valor de $\mathrm{R} \$ 200.000,00$ é financiado da seguinte forma: $10 \%$ de entrada e o restante pagos em 20 anos sob taxa mensal de $1 \%$ a.m.

A Tabela 3 exibe uma descrição inicial e final do financiamento.

Tabela 3: Tabela SAC

\begin{tabular}{|c|c|c|c|c|}
\hline $\mathbf{N}^{\mathbf{O}}$ da parcela & Amortização & Juros & Prestação & Saldo Devedor \\
\hline 0 & - & - & - & 180000 \\
\hline 1 & 750,00 & 1800,00 & 2550,00 & 179250,00 \\
\hline 2 & 750,00 & 1792,50 & 2542,50 & 178500,00 \\
\hline.. & $\ldots \ldots$ & $\ldots \ldots \ldots$ & $\ldots \ldots \ldots$ & $\ldots \ldots \ldots$ \\
\hline.. & $\ldots \ldots$ & $\ldots \ldots \ldots$ & $\ldots \ldots \ldots$ & $\ldots \ldots \ldots$ \\
\hline 239 & 750,00 & 15,00 & 765,00 & 750,00 \\
\hline 240 & 750,00 & 7,50 & 757,50 & 0,00 \\
\hline
\end{tabular}

No momento da consultoria, houve uma série de questionamentos quanto ao financiamento de casas populares, principalmente do Programa Minha Casa Minha Vida, do qual pelo menos $75 \%$ dos questionadores eram devedores [7]. A taxa média praticada é de $0,7 \%$ a.m. e o número máximo de parcelas é 360 (30 anos). Nesse momento, em especial, os consultores aplicaram as situações nos modelos desenvolvidos para esta finalidade e as dúvidas foram esclarecidas explicitando tempo e capital necessário para quitação dos referidos contratos. Observou-se que vários bancos oficiais disponibilizam simuladores para financiamento imobiliário e que as situações analisadas conduzem a resultados semelhantes aos obtidos. Além das informações obtidas na consultoria, vários sites foram apresentados para melhorar a compreensão e conhecimento em outras plataformas. Destacase nesta atividade que muitas das informações apresentadas foram consideradas estratégicas uma vez que, segundo muitos, não foram disponibilizadas no momento da contratação do financiamento.

\section{Considerações finais}

No Brasil, poucas escolas tem se preocupado em incluir sem seu plano de estudo, assuntos relacionados à Educação Financeira [8]. Segundo [11], a escola omite-se em relação às noções de comércio, de economia e finanças em geral. A inclusão deste tipo de atividade, apesar da dificuldade em cumprir o conteúdo programático mostrou-se muito eficiente para compreensão e fixação 
destes conceitos. A coordenação da escola onde se desenvolveram estas atividades, entendeu como uma nova forma de aprendizado proporcionando uma resposta muito positiva na grade curricular. Além disso, novos conteúdos foram inseridos discutindo o ensino da matematica financeira a partir de tópicos conhecidos tais como: PA, PG, funções do $1^{\circ}$ e $2^{\circ}$ graus, exponencial, logarítmica e polinomial, além de outros. Por fim, ressalta-se a inclusão de Educação Financeira na rede pública de ensino como uma necessidade social, possibilitando uma reflexão sobre finanças pessoais e planejamento financeiro.

\section{Referências}

[1] Assaf Neto,A. A Matemática Financeira e suas aplicações. 4ª ed, Atlas, São Paulo, 1998.

[2] Barbosa, J.M. et. all. Manual das Finanças Pessoais. Editorial Arcádia, Campinas, 2011.

[3] Caramelo, C. B. DA S, Oliveira, R.Z.G. Educação financeira: uma introdução através de um software, CQD - Revista Eletrônica Paulista de Matemática. Bauru, v. 10, p. 93-109, 2017.

[4] Cerbazi, G. Como organizar sua vida financeira, Ed. Sextante, São Paulo, 2015.

[5] Comite Nacional da Educação Financeira. Educação Financeira nas Escolas: ensino médio. 1 ed. rev, CONEF, Brasília - DF, 2013.

[6] Demo,P. Educar pela pesquisa. ed.9: Autores Associados, Campinas, 2011.

[7] Fanali, F.T. Aplicações das Finanças na Educação Básica, 2019, 63 p. Dissertação (Mestrado em Matemática em Rede Nacional), Faculdade de Ciências, Universidade Estadual Paulista "Julio de Mesquita Filho", 2019.

[8] Kern, D.T.B. Uma reflexão sobre a importância de inclusão de Educação Financeira na Escola Pública, 2009, 200 p. Dissertação (Mestrado Profissionalizante em Ensino de Ciências Exatas). Centro Universitário Univates, Lajeado - RS, 2009.

[9] Krugman, P.; Wells, R. Introdução a Economia. Elsevier, Rio de Janeiro, 2007.

[10] Leithold,L. Matemática aplicada à economia e administração. Harbra, São Paulo, 2001.

[11] Martins,J.P. Educação Financeira ao alcance de todos. Ed. Fundamento Educacional, São Paulo, 2004.

[12] Matta, R. O. B. Oferta e demanda de informação financeira pessoal: o programa de educação financeira do Banco Central do Brasil e os universitários do Distrito Federal, 2007. 214 p. Dissertação (Mestrado em Ciência da Informação) - Faculdade de Economia, Administração, Contabilidade e Ciência da Informação, Universidade de Brasília, Brasília, 2007.

[13] Morgado, A. C.; Carvalho, P. C. P. Matemática discreta. SBM, Rio de Janeiro, 2013.

[14] Morin, E.Os sete saberes necessários à educação do Futuro. Cortez, São Paulo, 2000.

[15] Morin, E.; Terena, M. Saberes globais e saberes locais: o olhar transdisciplinar. Garamond, Rio de Janeiro, 2000. 